\title{
Evolution Mechanism of Deformation and Failure of Surrounding Rock during Excavation and Unloading of the High-Stress Rock Mass
}

\author{
Wensong Xu $\left(\mathbb{D},{ }^{1,2}\right.$ Guangming Zhao $\left(\mathbb{D},{ }^{1,2}\right.$ Chongyan Liu ${ }^{1 D},{ }^{1,2}$ Xiangrui Meng, \\ Ruofei Zhang, ${ }^{1,2}$ Siming Kao, ${ }^{1,2}$ Shunjie Huang $\mathbb{D}^{1,2}{ }^{1,2 u n}$ Zhou, $^{1,2}$ and Rui Peng ${ }^{3}$ \\ ${ }^{1}$ State Key Laboratory of Mining Response and Disaster Prevention and Control in Deep Coal Mines, \\ Anhui University of Science and Technology, Huainan 232001, China \\ ${ }^{2}$ School of Mining and Safety Engineering, Anhui University of Science and Technology, Huainan 232001, China \\ ${ }^{3}$ North China Institute of Science \& Technology, Beijing 101601, China
}

Correspondence should be addressed to Wensong Xu; 359879021@qq.com, Guangming Zhao; guangmingzhao@163.com, and Chongyan Liu; 1578801793@qq.com

Received 30 September 2020; Revised 16 October 2020; Accepted 7 November 2020; Published 25 November 2020

Academic Editor: Chun Zhu

Copyright ( $\odot 2020$ Wensong Xu et al. This is an open access article distributed under the Creative Commons Attribution License, which permits unrestricted use, distribution, and reproduction in any medium, provided the original work is properly cited.

\begin{abstract}
To deeply analyze the failure evolution of surrounding rock during excavation-induced unloading of the high-stress rock mass, a multistage failure model was established based on revealed failure patterns. The critical conditions for wing cracks were determined. The slab crack buckling analysis was carried out. The true-triaxial rockburst testing system was used for the miniature model test to study the fracturing evolution of surrounding rocks during excavation-induced unloading of the high-stress rock mass. The research results indicated that harder rock samples had higher compressive strength. Moreover, the smaller peak strains implied more obvious yield/plastic stages of harder rock samples with high confining pressures and softer rock samples with low confining pressures. V-shaped grooves appeared at the beginning of the surrounding rock's failure while spalling and splitting occurred as the stress increased. Finally, the entire sample's overall splitting failure was observed, and the borehole bottom bulged upward. The harder rock masses had fewer fractures and higher degrees of failure. There were obvious V-shaped grooves on both sides of the marble cave wall. The tensile failure occurred near the opening surface and shear failure at a far distance. The sandstone's overall failure was related to tensile cracking, and splitting failure occurred far away from the opening surface, which was similar to the in situ failure of surrounding rocks during excavation-induced unloading of the high-stress rock mass. The results obtained are instrumental in the construction safety control and prevention of underground engineering disasters.
\end{abstract}

\section{Introduction}

With the development of coal and other industries [1], deep mining is inevitable and the environment is facing more complex problems $[2,3]$. Excavations of high-stress rock masses disturb their original stress-strain state and structure, resulting in the stress release at the excavation boundaries and drastic redistribution of stress fields and strain energy of surrounding rocks. This involves cracking, particles' ejection, splitting into flakes, buckling to the point of rupture, fragments' ejection, propagating deep cracks in surrounding rocks, and even strong dynamic disasters.
The main failure modes of deep rock masses are different from those of shallow ones. They are mainly stress-driven brittle fracture failure and chipping [4]. Due to the complex geological conditions in underground engineering applications $[5,6]$, these failure modes are classified by their mechanism as large-scale deformation of roadway-surrounding soft rocks, zonal fracture phenomenon [7-10], hard dynamic failure (e.g., rockburst) of roadway-surrounding soft rocks [11, 12], and so forth. Numerical simulations and field experiments indicated that excavationinduced unloading violated the original stress balance, resulting in redistribution of the surrounding rocks' stress 
fields near the roadway. When the stress exceeded the strength limit of surrounding rocks, failures expanded from the excavation/working face to the rock mass bulk. The zone between the working face and the rock mass bulk is referred to as the excavation disturbance zone [11-16]. Zhang et al. [17] studied the fracturing of surrounding rocks caused by the excavation unloading of deep underground tunnels and analyzed the mechanism and influencing factors of fracturing surrounding rocks quasistatic and transient excavation unloading. Wang et al. [18] examined the local failure characteristics of rocks under loading and unloading conditions, the tensile stress generation in the rock bulk during loading/unloading, and its effect on rocks' failure mode. Li et al. [19] reported that the maximum tangential stress is the main factor controlling the tensile failure in the high-stress rock mass during excavation unloading. Meanwhile, Zhang et al. [20] proved that failures at low and high confining pressures were tensile fracture and shear failure, respectively. $\mathrm{Xu}$ et al. $[21,22]$ conducted a single-sided unloading test to obtain the failure evolution law of single-side unloaded surrounding rocks and revised the Drucker-Prager criterion based on the double reduction of strength. However, most of the above studies used the experimental results on rock samples, which implied some discrepancies between these test results and field measurements. Therefore, they failed to properly reflect the stress evolution pattern under the confining pressure variation's real conditions.

Deformations and failures of surrounding rocks during excavation unloading of high-stress rock mass were analyzed through theoretical calculations and miniature model tests. The fracturing mechanism of surrounding rocks caused by unloading was studied; criteria for judging the damage of surrounding rocks were determined. On this basis, deformation and failures of surrounding rocks during excavation unloading of high-stress rock mass were revealed, providing a theoretical basis for controlling surrounding rocks.

\section{Deformation and Failures of Surrounding Rocks during Excavation Unloading of High- Stress Rock Mass}

2.1. The Failure Mode of Surrounding Rock during Unloading of High-Stress Rock Mass Excavation. Diederich et al. [23] combined indoor experiments, numerical simulations, theoretical analysis, and other methods to study the cracking and spalling phenomenon during tunnel excavation and compared with the envelope of the Hoek-Brown (HB) strength criterion to obtain the empirical-theoretical criterion curve of splitting failure, featuring the effective principal stresses and uniaxial compressive strength, as shown in Figure 1. The concentrated strength envelope divides the principal stress plane into different areas, corresponding to different failure forms in actual surrounding rocks.

2.2. Mechanical Model of Surrounding Rock Failure during Excavation and Unloading of High-Stress Rock Mass. Figure 2 shows an oblong roadway of high-stress rock mass excavation, where $R$ is the roadway radius, $p_{0}$ is the vertical stress, $\lambda p_{0}$ is the horizontal ground stress, and $\lambda$ is the lateral pressure coefficient.

After the full-section excavation of the roadway is formed and the stress adjustment is completed, the stress field of the surrounding rock can be approximated by the elastic solution for a thick-walled cylinder subjected to external pressure:

$$
\begin{aligned}
\sigma_{r} & =\frac{p_{0}}{2}\left[(1+\lambda)\left(1-\frac{R^{2}}{r^{2}}\right)-(1-\lambda)\left(1-4 \frac{R^{2}}{r^{2}}+3 \frac{R^{4}}{r^{2}}\right) \cos (2 \theta)\right], \\
\sigma_{\theta} & =\frac{p_{0}}{2}\left[(1+\lambda)\left(1+\frac{R^{2}}{r^{2}}\right)-(1-\lambda)\left(1+3 \frac{R_{4}}{r^{2}}\right) \cos (2 \theta)\right], \\
\tau_{r \theta} & =\frac{p_{0}}{2}(1-\lambda)\left(1+2 \frac{R^{2}}{r^{2}}-3 \frac{R^{4}}{r^{2}}\right) \sin (2 \theta),
\end{aligned}
$$

where $\sigma_{r}$ and $\sigma_{\theta}$ are the radial and hoop stresses of surrounding rocks; $R$ is the radius of the tunnel; and $r$ is the distance to the center of the tunnel.

2.2.1. Crack Propagation Model during the Excavation of High-Stress Rock Mass. Figure 3 shows the main crack in the tunnel-surrounding rock, with a length of $2 a$ and an angle $\alpha$ to the tunnel's radial direction. The normal stress $\sigma_{n}$ and the shear stress $\tau$ acting on the crack plane are expressed as

$$
\begin{aligned}
\sigma_{n} & =\frac{1}{2}\left(\sigma_{r}+\sigma_{\theta}\right)+\frac{1}{2}\left(\sigma_{r}-\sigma_{\theta}\right) \cos (2 \alpha), \\
\tau & =\frac{1}{2}\left(\sigma_{r}-\sigma_{\theta}\right) \sin (2 \alpha)
\end{aligned}
$$

where $\sigma_{n}$ and $\sigma_{\theta}$ are the normal and hoop stresses of the tunnel-surrounding rocks.

When the crack is in a bidirectional compressive stress state, the crack is closed under pressure, friction occurs between the crack surfaces, and relative sliding occurs under the effect of effective shear stress $\tau_{\text {eff }}$. Hence, it is a Mode II crack, and the stress intensity factor (SIF) $K_{\text {II }}$ of the crack tip is

$$
K_{\mathrm{II}}=\tau_{\text {eff }} \sqrt{\pi \alpha}
$$

where $\tau_{\text {eff }}=\tau-f_{r} \sigma_{n}$ and $f_{r}$ is the sliding friction coefficient of the crack surface.

When $\tau_{\text {eff }}$ reaches the critical value, the crack starts to expand, and the initial crack tip will produce wing crack. Wing crack is a Mode I crack, and its SIF is

$$
K_{\mathrm{I}}(\beta)=\frac{3}{2} \sin \beta \cos \frac{\beta}{2} K_{\mathrm{II}}
$$

According to the maximum tensile stress criterion, the initial propagation direction of the wing crack is $\beta= \pm 70.5^{\circ}$. The obtained propagation direction angle $\beta$ is substituted into the $K_{\mathrm{I}}$ expression, and when the wing crack starts, the SIF under the compressive shear stress is expressed as 


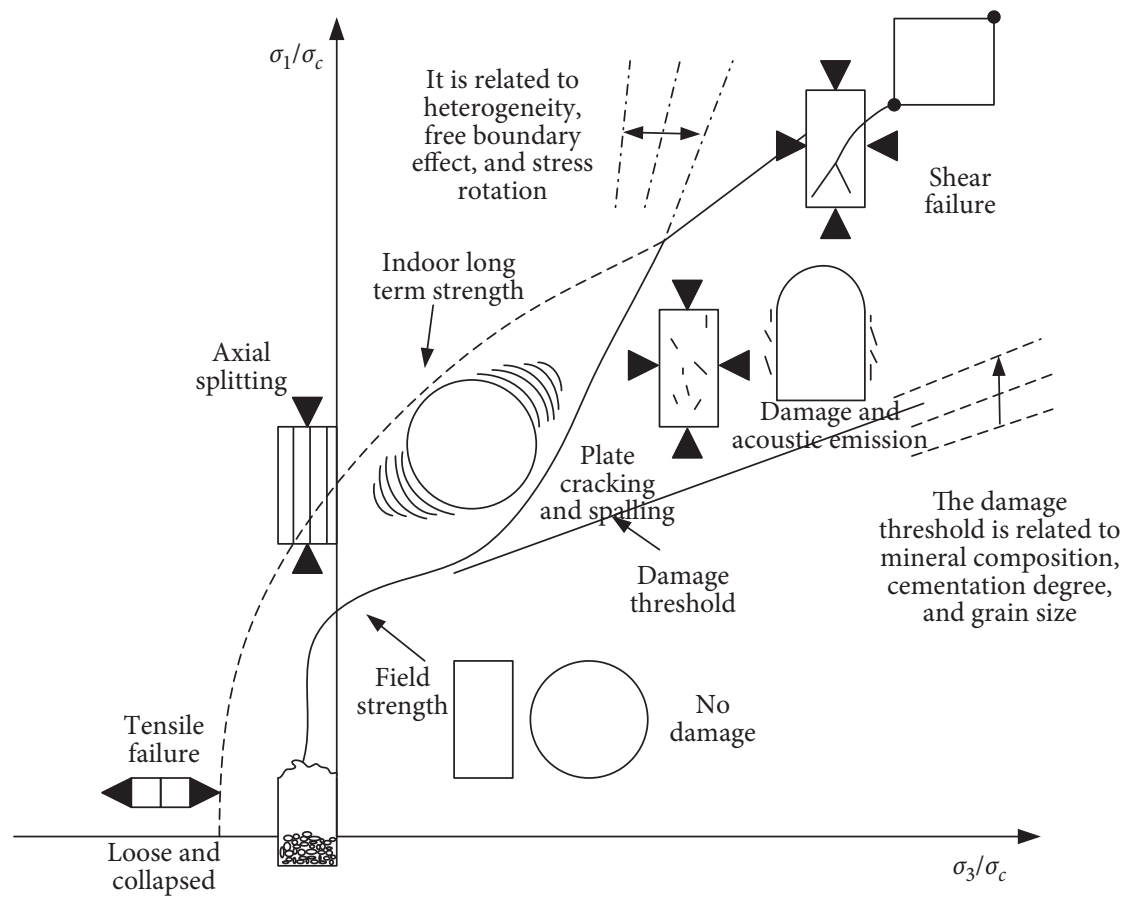

Figure 1: The empirical-theoretical criterion curve of excavation failure of high-stress rock mass.

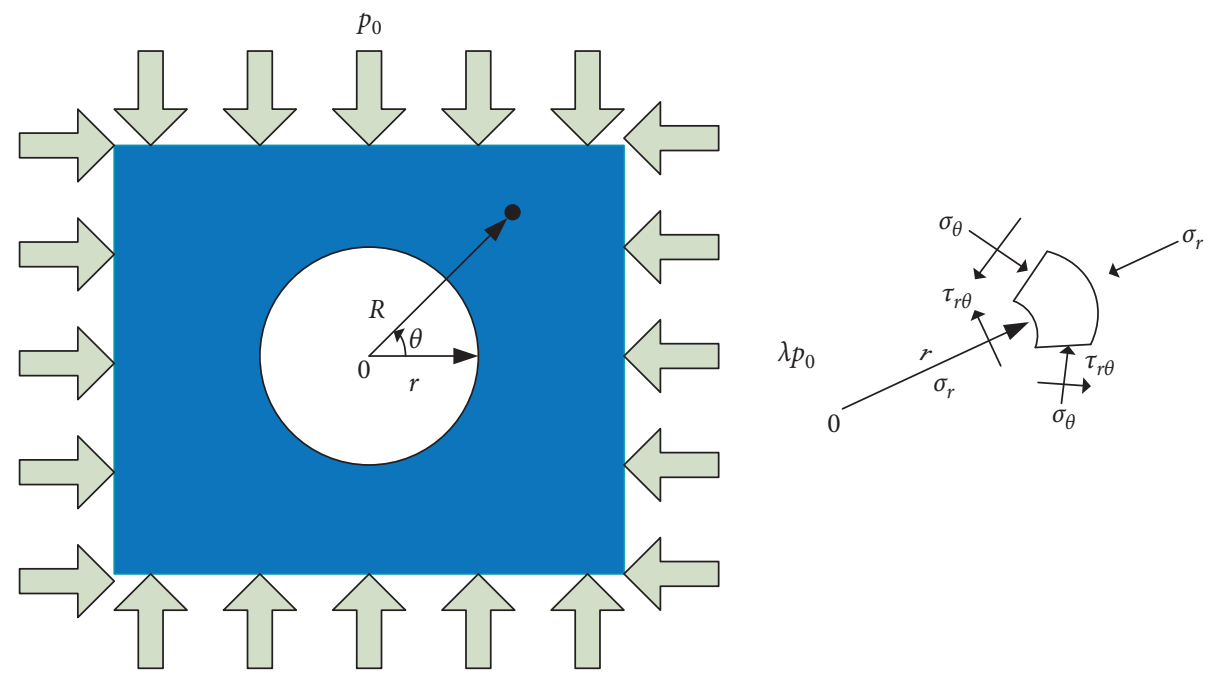

FIGURE 2: Secondary stress calculation model of surrounding rocks during high-stress rock mass excavation.

$$
K_{\mathrm{I}}=\frac{2}{\sqrt{3}} K_{\mathrm{II}}
$$

When the crack is under two-way tension or one-way compression, the fracture surface undergoes shear sliding under the effect of shear stresses. Meanwhile, under the effect of the first normal tensile stress, the fracture surface will also undergo normal tension. Under the shear stress state, the crack is a mixed-mode crack controlled by the shear stress $\tau$ and the normal tensile stress $\sigma_{n}$.

For the mixed-mode crack of known geometry, the stress field at the crack tip can be calculated, and the stress $\sigma_{\beta}$ at the extended wing crack can be expressed as follows:

$$
\sigma_{\beta}=\frac{1}{\sqrt{2 \pi r}} \cos \frac{\beta}{2}\left(\sigma_{n} \sqrt{\pi \alpha} \cos ^{2} \frac{\beta}{2}-\frac{3 \tau \sqrt{\pi \alpha}}{2} \sin \beta\right) .
$$

The SIF in the crack tip is derived as

$$
K_{\mathrm{I}}=\lim _{r \longrightarrow 0} \sqrt{2 \pi r \sigma_{\beta}}
$$

Hence, we get

$$
K_{I}(\beta)=\cos \frac{\beta}{2}\left(\sigma_{n} \sqrt{\pi \alpha} \cos ^{2} \frac{\beta}{2}-\frac{3 \tau \sqrt{\pi \alpha}}{2}\right) \sin \beta .
$$




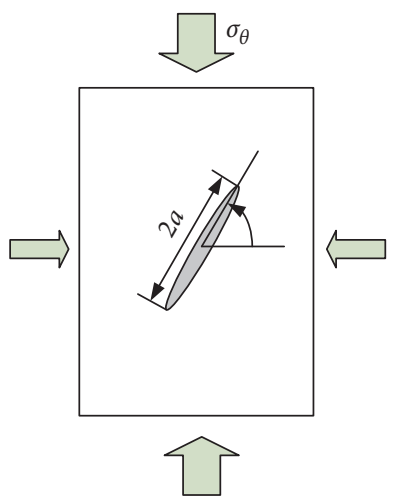

(a)

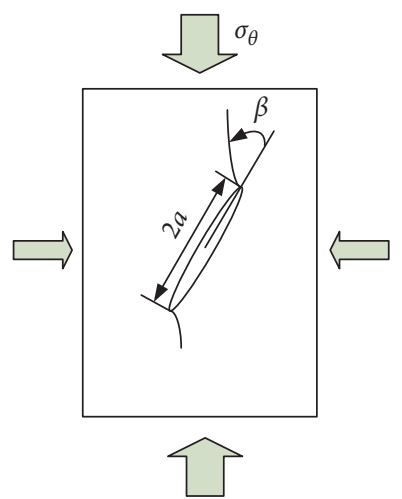

(b)
FIGURE 3: Crack propagation model under bidirectional compression: (a) initial crack and (b) wing crack propagation.

When the SIF reaches a certain critical value, the crack starts to expand. Taking the partial derivative of equation (8) and setting it to zero, we get

$$
2 \tau \tan ^{2} \frac{\beta}{2}-\sigma_{n} \tan \frac{\beta}{2}-\tau=0 .
$$

The crack inclination angle $\beta_{0}$ of the wing crack can be obtained from the above equation:

$$
\tau_{\text {eff }}=\frac{\sigma_{\theta}}{2}\left\{(1-k) \sin (2 \alpha)-f_{r}[1+k+(1-k) \cos (2 \alpha)]\right\} .
$$

2.2.2. Critical Conditions for Wing Cracks. To investigate the effect of confining pressure $\sigma_{r}$ on the cracking mode and range of cracks, a coefficient $k=\sigma_{r} / \sigma_{\theta}$ is introduced. Under hydrostatic pressure, the effective shear stress between the crack surfaces can be derived as

$$
K_{\mathrm{I}}-\sqrt{\frac{\pi \alpha}{3}} \sigma_{\theta}\left\{(1-k) \sin (2 \alpha)-f_{r}[1+k+(1-k) \cos (2 \alpha)]\right\} .
$$

Then, the SIF of the wing crack initiation under the twoway compression stress state can be expressed as

$$
Y=\frac{K_{\mathrm{I}}}{p_{0} \sqrt{\pi a}}=\frac{2 \sqrt{3}}{3}\left\{\frac{1-k}{1+k} \sin (2 \alpha)-f_{r}\left[1+\frac{1-k}{1+k} \cos (2 \alpha)\right]\right.
$$

The initial SIF of the wing crack $\left(K_{\mathrm{I}}\right)$ is related to the stressed state $\sigma_{\theta}, k$, the crack length $a$, and the friction coefficient $f_{r}$. The stress $\sigma_{\theta}$ of surrounding rocks is a function of the far stress $p_{0}$. Both sides of the equation are divided by $p_{0} \sqrt{\pi a}$ simultaneously, and the dimensionless parameter $Y=K_{\mathrm{I}} / p_{0} \sqrt{\pi a}$ is introduced, which reflects the ratio $k$ of radial stress to hoop stress, friction coefficient $f_{r}$, and the effect of crack inclination angle $\alpha$ on KI.

The compressive strength $\sigma_{c}$ of rock mass has the following statistical relationship with crack arrest toughness $K_{I C}$ :

$$
\sigma_{c}=(55-82) K_{I C} .
$$

From equations (11)-(13), we get

$$
\begin{aligned}
& r_{c}=\left\{\frac{2(55-82) p_{0} \sqrt{\pi a} \sin (2 \alpha)-f_{r} \cos (2 \alpha)}{\sqrt{3 \sigma_{c}}+2(55-82) f_{r} p_{0} \sqrt{\pi a}}\right\}^{1 / 2} R, \\
& k_{c}=\frac{r^{2}-R^{2}}{r^{2}+R^{2}} .
\end{aligned}
$$

2.2.3. Analysis of Slab Crack Buckling. During excavation unloading of the high-stress rock mass, the rock mass on the working surface is under three-way five-sided force, and a through-type crack parallel to the wall is generated due to the free wall being pulled by pressure. When the stress exceeds its critical buckling value, surrounding rocks near the roadway undergo the instability failure, and the slabbeam instability mechanical model supported by brittle springs is used for analysis. The results are shown in Figure 4.

According to the failure mechanism of the slab-beam structure, the elastic performance at the working surface of the slab-beam is expressed as follows:

$$
V=\frac{D}{2} \int_{0}^{1} \int_{0}^{b}\left\{\left(\frac{\partial^{2} w}{\partial^{2} x^{2}}+\frac{\partial^{2} w}{\partial y^{2}}\right)+2(1-\mu)\left[\left(\frac{\partial^{2} w}{\partial x \partial y}\right)^{2}-\frac{\partial^{2} w}{\partial x^{2}}-\frac{\partial^{2} w}{\partial y^{2}}\right]\right\} \mathrm{d} x \mathrm{~d} y
$$

where $D=E t^{2} / 12\left(1-\mu^{2}\right)$.

The work done by the external force is the work $\mathrm{d} P=$ $\sigma_{c r} t \mathrm{~d} y$ produced when the two ends of the slab approaching each other, integrated along the slab width $b$ :

$$
U=\frac{1}{2} \int_{0}^{1} \int_{0}^{b} \sigma_{c r} t \mathrm{~d} y\left(\frac{\partial w}{\partial x}\right)^{2} \mathrm{~d} x .
$$

If

$$
w(x, y)=A\left(1-\cos \frac{2 \pi x}{a}\right) \sin \frac{\pi y}{b},
$$

equation (16) is brought and integrated; considering $\partial(V-U) / \partial A$, it is easy to obtain the critical stress:

$$
\sigma_{c r}=\frac{\pi^{2} D}{l^{2} t}\left[4+2\left(\frac{l}{b}\right)^{2}+3\left(\frac{l}{b}\right)^{4}\right] .
$$

Regardless of the interaction between the slabs, in the elastic state, for a wide slab, $b \gg 1$, the critical stress is 


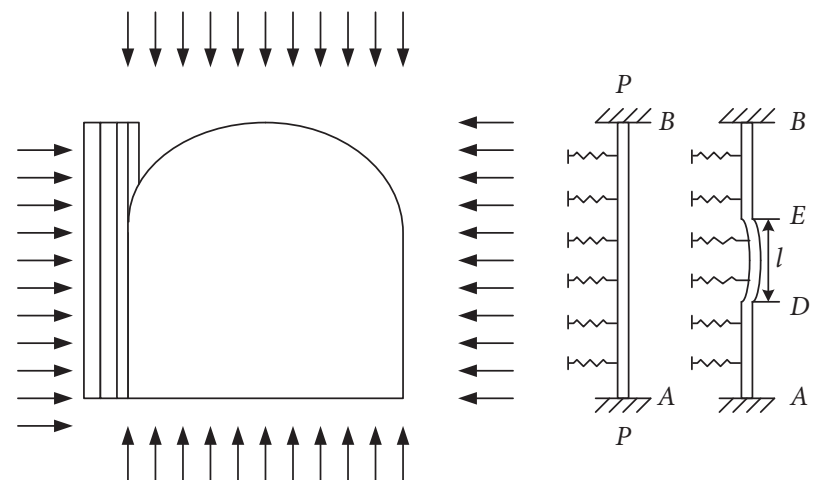

FIGURE 4: Mechanical model of slab-beam instability.

$$
\sigma_{c r}=\frac{E}{1-\mu^{2}} \frac{\pi^{2} t^{2}}{3 l^{2}}
$$

Considering the mutual influence between the slabs, the critical stress is expressed as

$$
\sigma_{c r}=\frac{E}{1-\mu^{2}} \frac{\pi^{2} t^{2}}{3 l^{2}}+\sum_{i=1}^{n} \frac{G}{\lambda_{i}} h
$$

where $n$ is the number of contact surfaces between the slabs and $\lambda_{i}$ is the effective length of the $i$-th contact surface.

The above equation indicates that the critical stress is related to the elastic modulus $E$ and Poisson's ratio of the material and depends on the size of the peeled-off fragment.

The control differential equation is as follows:

$$
D \nabla^{4} w+P_{x} \frac{\partial^{2} w}{\partial x^{2}}+P_{y} \frac{\partial^{2} w}{\partial y}=0
$$

The boundary conditions are

$$
\begin{aligned}
& w=0, \frac{\partial^{2} w}{\partial x^{2}}=0, \exists x=0, a, \\
& w=0, \frac{\partial^{2} w}{\partial y^{2}}=0, \exists y=0, b .
\end{aligned}
$$

The solution of $w$ is

$$
w=\sum_{m=1}^{\infty} \sum_{n=1}^{\infty} A_{m n} \sin \frac{m \pi x}{a} \sin \frac{n \pi y}{b} .
$$

Equation (23) is brought to obtain

$$
\sum_{m=1}^{\infty} \sum_{n=1}^{\infty} A_{m n}\left\{\pi^{2} D\left[\left(\frac{m}{a}\right)^{2}+\left(\frac{n}{b}\right)^{2}\right]-\left[P_{x}\left(\frac{m}{a}\right)^{2}+P_{y}\left(\frac{n}{b}\right)^{2}\right] \sin \frac{m \pi x}{a} \sin \frac{n \pi x}{b}=0 .\right.
$$

Introducing dimensionless parameters,

$$
\begin{aligned}
& \bar{P}_{x}=\frac{P_{x}}{\left(\pi^{2} D / a^{2}\right)}, \\
& \bar{P}_{y}=\frac{P_{y}}{\left(\pi^{2} D / b^{2}\right)} .
\end{aligned}
$$

Equation (24) can be written as

$$
\frac{\bar{P}_{x}}{(a / b)^{2}\left(m+(n / m)\left(a^{2} / b^{2}\right)\right)^{2}}+\frac{\bar{P}_{y}}{\left(n+\left(m^{2} / n\right)\left(b^{2} / a^{2}\right)\right)^{2}}=1 .
$$

$$
\sigma_{x}=\frac{p_{0} a^{2}(1+\lambda)}{2\left(a^{2}+4 y^{2}\right)}\left(1-\frac{4 r^{2}}{a^{2}+4 y^{2}}\right)-\frac{p_{0} a^{2}(1-\lambda)}{2\left(a^{2}+4 y^{2}\right)}
$$

$$
\cdot\left(1-\frac{16 r_{0}^{2}}{a^{2}+4 y^{2}}+\frac{48 r_{0}^{2}}{\left(a^{2}+4 y^{2}\right)^{2}}\right) \frac{4 y^{2}-a^{2}}{4 y^{2}+a^{2}}
$$$$
+\frac{4 p_{0} y^{2}}{2\left(a^{2}+4 y^{2}\right)}\left[(1+\lambda)\left(1+\frac{4 r_{0}^{2}}{a^{2}+4 y^{2}}\right)\right.
$$$$
\left.\cdot(1-\lambda)\left(1+\frac{48 r_{0}^{4}}{\left(a^{2}+4 y^{2}\right)^{2}}\right) \frac{4 y^{2}-a^{2}}{4 y^{2}+a^{2}}\right]
$$

When the variable length ratio is $\alpha$, the thin slab has only one sine wave $m=1$ and $n=1$ in both $X$ and $Y$ directions. This equation shows that there is a straight-line relationship between $\bar{P}_{x}$ and $\bar{P}_{y}$ : 


\section{Miniature Model Test Plan Design of Excavation Unloading of High-Stress Rock Mass}

3.1. Sample Preparation. To better analyze failures of highstress rock masses during excavation unloading in underground engineering, the simulation tests were performed on typical marble and sandstone samples with a uniform texture and good integrity, which were processed into $100 \mathrm{~mm} \times 100 \mathrm{~mm} \times 100 \mathrm{~mm}$ cubes with a circular hole of $30 \mathrm{~mm}$ in diameter, as shown in Figure 5.

3.2. Test Equipment. The test equipment adopted the selfdeveloped true-triaxial rock test system. To observe the tunnel wall stress and the evolution of deformation and failures in real time during the loading process, a miniature camera was used for real-time monitoring, as shown in Figure 6.

3.3. Design of the Test Plan. The cubic sample with holes was tested on the true-triaxial rock test system to obtain the failure characteristics of surrounding rocks during excavation-induced unloading of the high-stress rock mass. The simulation test involved stress-controlled loading with loading rates of the first, second, and third principal stresses of 3, 1 , and $0.5 \mathrm{MPa} / \mathrm{min}$, respectively, in which load increments were added to the initial stresses depicted. While sandstone excavation is mostly used in mining projects, marble excavation is mostly applied to tunnels and water conservancy projects. Therefore, the vertical stress in these tests was the maximum principal stress, so the tunnel's excavation direction was perpendicular to the maximum principal stress. Due to such factors as the crustal movement, the horizontal stress ratio to the vertical stress had a decreasing trend. When the depth exceeded a certain range, the horizontal stress value exceeded the vertical one, and the horizontal stress was the maximum principal stress. Therefore, the excavation direction of the roadway was parallel to the maximum principal stress. Figure 7 shows the stress-loading path during the test. The stress value was first increased to the initial stress level listed in Table 1, with the abovementioned loading rates of 3,1 , and $0.5 \mathrm{MPa} / \mathrm{min}$, respectively. After reaching the initial stress level, stresses in the $X$ and $Y$ directions remained unchanged, while that in the $Z$ direction was increased at the loading rate of $3 \mathrm{MPa} /$ min until failure.

\section{Fracture Evolution of Surrounding Rocks during Excavation-Induced Unloading of High-Stress Rock Mass}

\subsection{Strength of Surrounding Rocks during Excavation-Induced Unloading of High-Stress Rock Mass}

4.1.1. Marble. The uniaxial loading axial stress-strain curves of marble samples are depicted in Figure 8. As shown in Figure $8(\mathrm{a})$, the uniaxial compressive strength of marble is $88 \mathrm{MPa}$, and its stress-strain curves can be subdivided into five stages: (1) initial compaction, (2) linear elastic section, (3) elastoplastic transition, (4) yield or plastic section, and (5) postpeak section. Figure 8(b) shows stress-strain curves with confining pressure for the marble sample. The failure strength is $153 \mathrm{MPa}$, exceeding the uniaxial compressive strength by $65 \mathrm{MPa}$. The peak point's strain value is also significantly increased, and there is a clear trend in the postpeak yield stage. The postpeak stress drop rate of the sample with holes is significantly larger than that of the intact sample. Simultaneously, the former's brittleness coefficient is larger, indicating a certain difference between the mechanical failure characteristics of percolated and intact rock masses.

4.1.2. Sandstone. The uniaxial loading axial stress-strain curves of sandstone samples are depicted in Figure 9. As shown in Figure 9(a), sandstone's uniaxial compressive strength is $64.4 \mathrm{MPa}$, and its stress-strain curves can be subdivided into the same five stages as those of marble samples. Figure 9(b) shows the stress-strain curves of sandstone samples with confining pressure. The failure strength is $83.6 \mathrm{MPa}$, which exceeds the uniaxial compressive strength by $19.2 \mathrm{MPa}$. The tendency of the third (elastoplastic transition) stage is obvious. The strain value at the first (compaction) stage is larger than that at uniaxial loading, and the strain value of the second (linear elastic) stage is smaller than that of the uniaxial loading.

As seen in Figures 8 and 9, the harder the rock sample, the higher its compressive strength. Moreover, the smaller are the peak strains, the more obvious are the yield/plastic stages of harder rock samples with high confining pressures and softer rock samples with low confining pressures.

4.2. Failure Characteristics of Surrounding Rocks during Excavation-Induced Unloading of High-Stress Rock Mass. As shown in Figures 10(a) and 10(b), cracks in marble samples originated from the left and right side walls and expanded outward. With an increase in the axial pressure, cracks originated from the left and right side walls to the left top arch and right bottom arch and expanded outward. Eventually, shear failure occurred throughout the entire sample. Meanwhile, cracks in sandstone samples also originated from the left and right side walls and expanded outward. As the axial pressure increased, the sample deformation developed in the direction of the minimum principal stress. A slab crack appeared in the direction of the minimum principal stress, and the bottom was shifted upwards. Finally, the overall splitting failure occurred throughout the entire sample, and the bottom bulged upwards.

The above fracture evolution stages were similar to those observed during excavation unloading of the high-stress rock mass, indicating that the simulation test was reasonable and effective. To better describe the evolution process of deformation and failure of surrounding rocks, the following parameters were analyzed using the recorded videos, whose scans are given in Figure 11. 


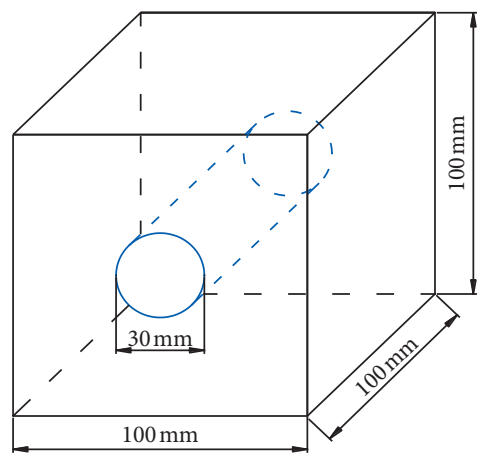

(a)

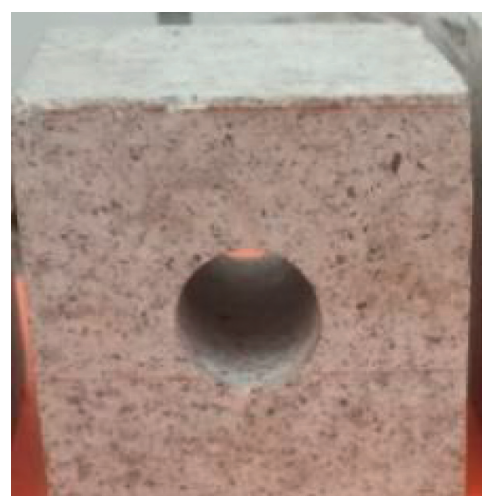

(b)

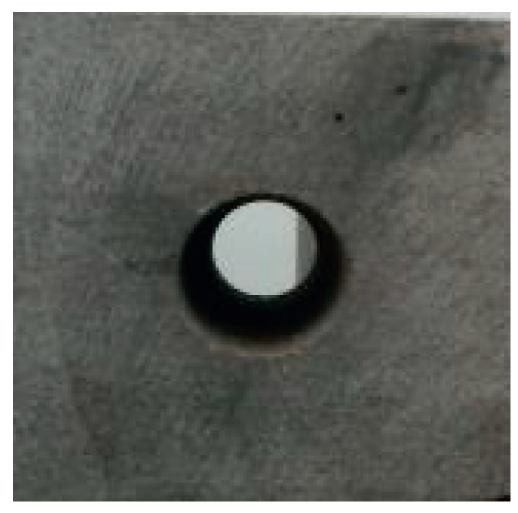

(c)

FIgURE 5: Cube sample used in the test. (a) Schematic diagram of the sample model. (b) Marble sample. (c) Sandstone sample.

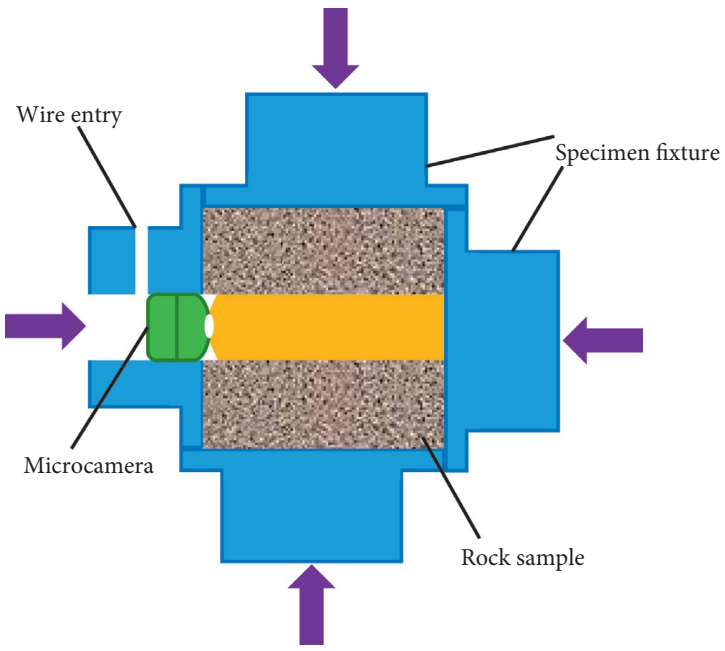

(a)

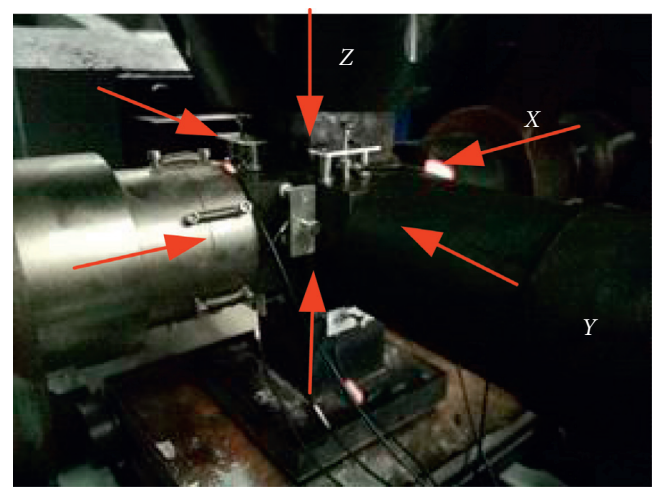

(b)

FIGURE 6: Real-time video monitoring of the internal structure failure of three-dimensional loading rock samples: (a) schematic diagram of the installation of the miniature camera and (b) schematic diagram of the triaxial loading.

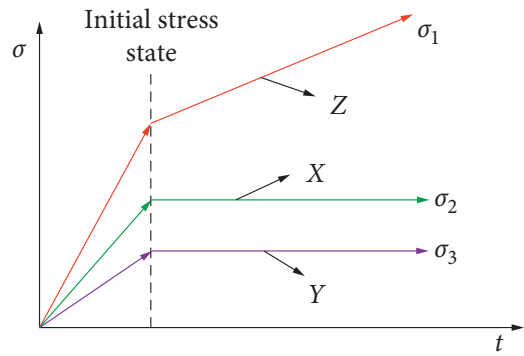

(a)

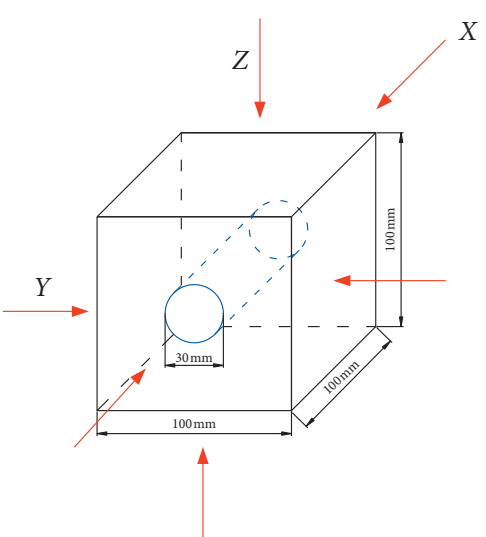

(b)

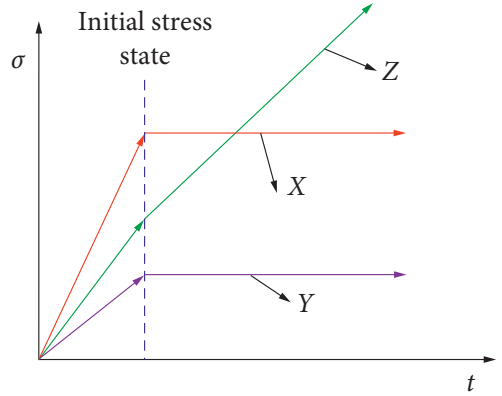

(c)

Figure 7: True-triaxial loading stress path.

4.2.1. Marble Failure Evolution Characteristics. After the sample installation in the testing machine, a microcamera was used for monitoring and recording; the triaxial loading in $X, Y$, and $Z$ directions was provided with the loading rates of $1,0.5$, and $3 \mathrm{MPa} / \mathrm{min}$, respectively. After loading to the initial stress level, the $X$ and $Y$ stresses were kept unchanged, 
TABLE 1: The initial stress values.

\begin{tabular}{lccc}
\hline Number & $\sigma_{1}(\mathrm{MPa})$ & $\sigma_{2}(\mathrm{MPa})$ & $\sigma_{3}(\mathrm{MPa})$ \\
\hline $1 \#$ & 30 & 20 & 10 \\
$2 \#$ & 30 & 20 & 10 \\
\hline
\end{tabular}

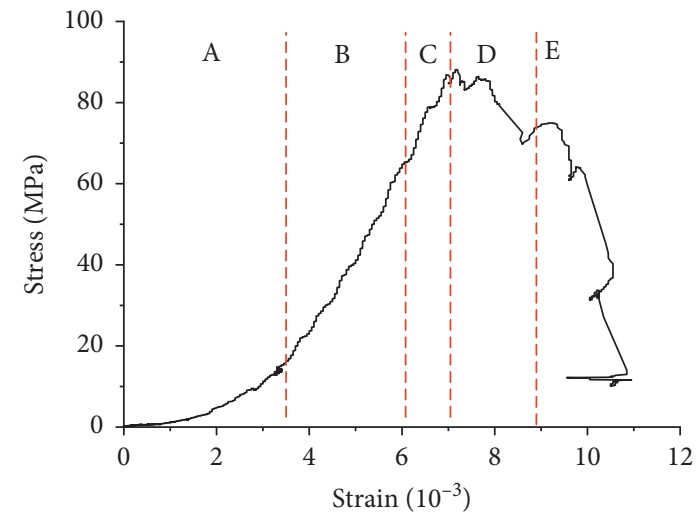

- Stress and strain

A Initial compaction stage

B Linear elastic stage

C Elastic plastic transition

stage

D Yield stage

E Queen stage

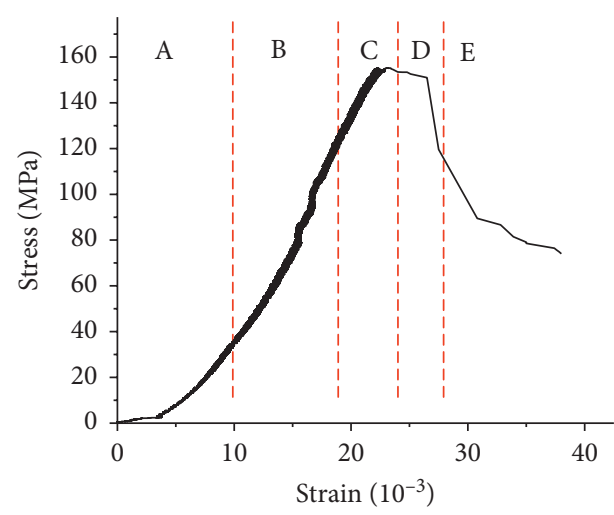

_- Stress and strain

A Initial compaction stage

B Linear elastic stage

C Elastic plastic transition

stage

D Yield stage

E Queen stage

(a)

(b)

FIGURE 8: Stress-strain curves of marble samples: (a) uniaxial stress-strain curves and (b) stress-strain curves of samples with a borehole plus confining pressure.

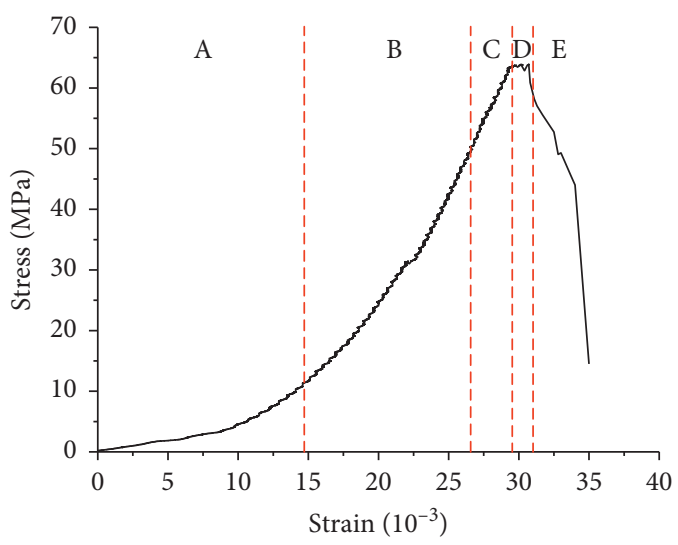

- Stress and strain

A Initial compaction stage

B Linear elastic stage

C Elastic plastic transition

stage

D Yield stage

E Queen stage

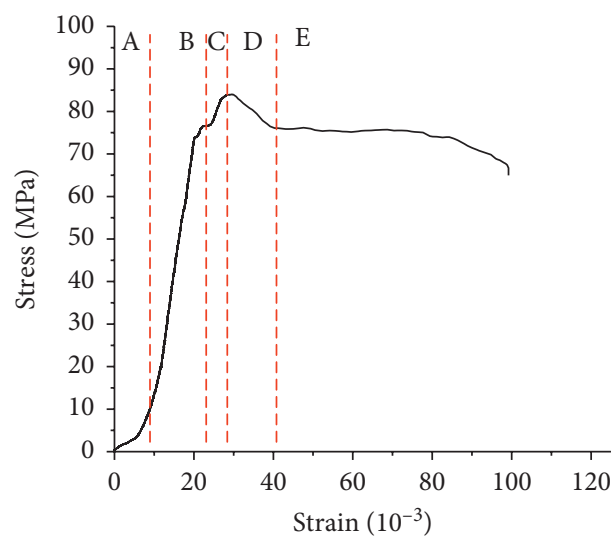

Stress and strain

A Initial compaction stage

B Linear elastic stage

C Elastic plastic transition

stage

D Yield stage

E Queen stage

FIGURE 9: Stress-strain curves of sandstone samples. (a) uniaxial stress-strain curves and (b) stress-strain curves of samples with holes plus confining pressure. 


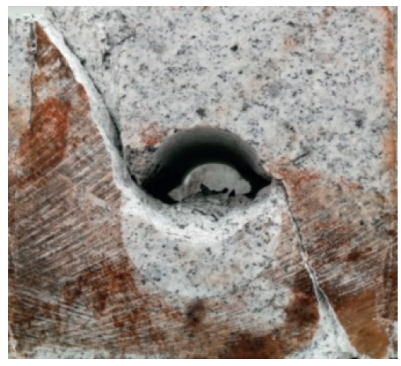

(a)

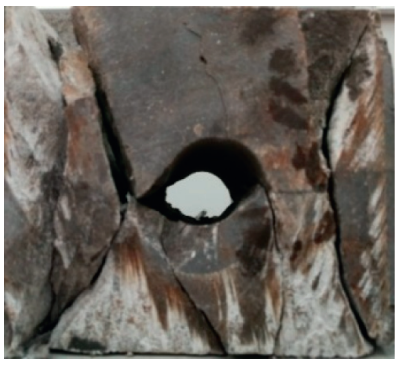

(b)

FIgURE 10: The overall failure of the sample: (a) marble and (b) sandstone.

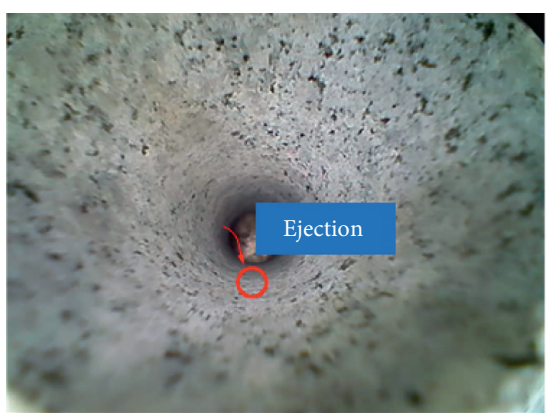

(a)

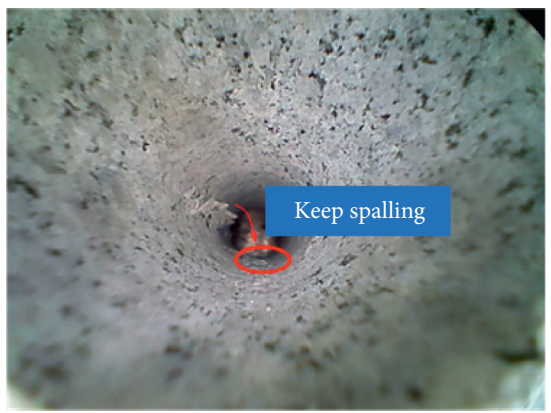

(d)

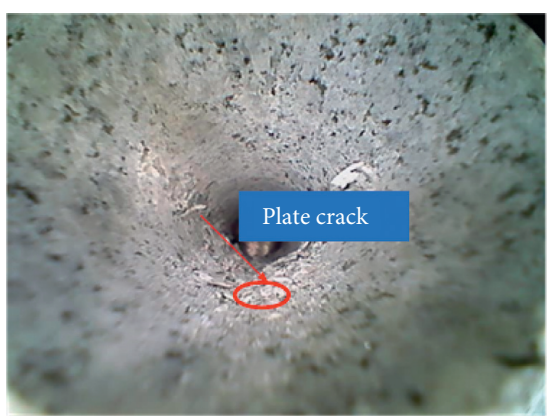

(g)

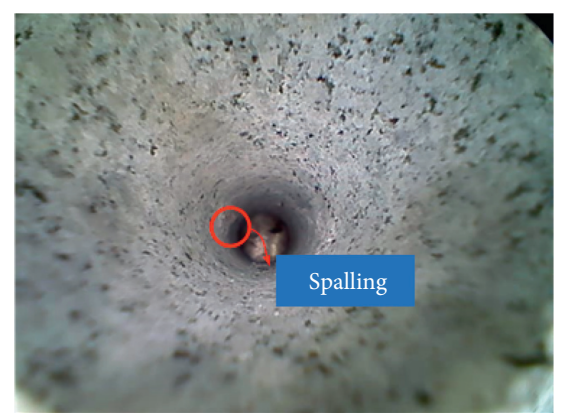

(b)

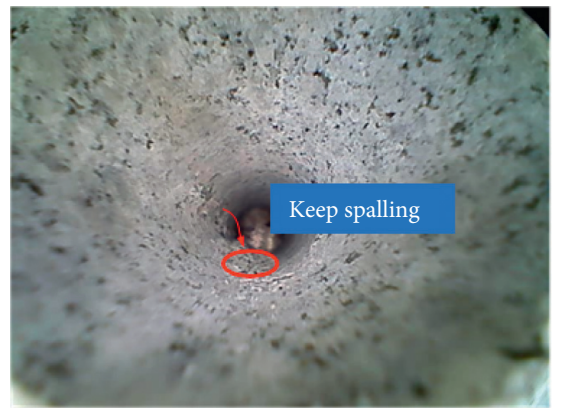

(e)

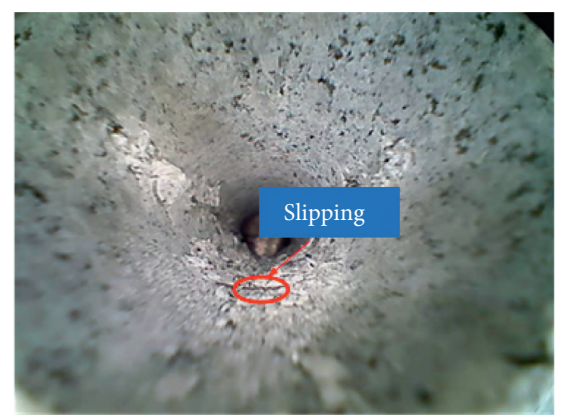

(h)

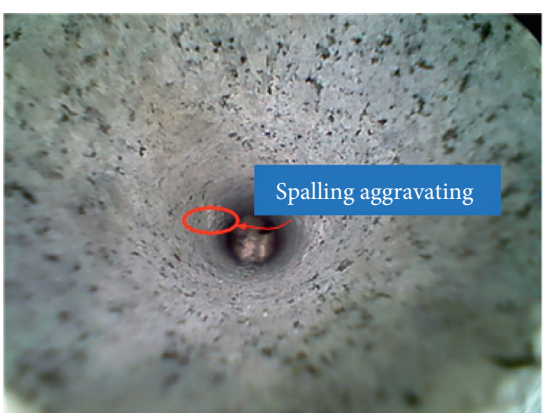

(c)

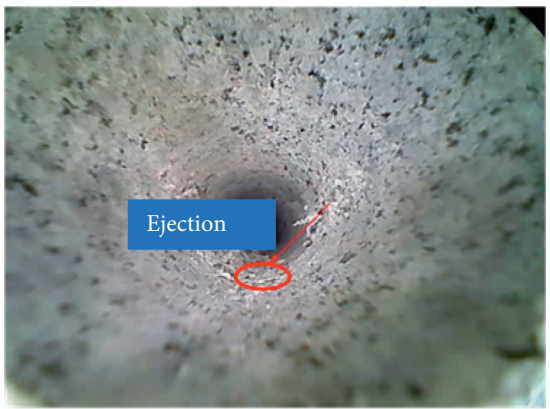

(f)

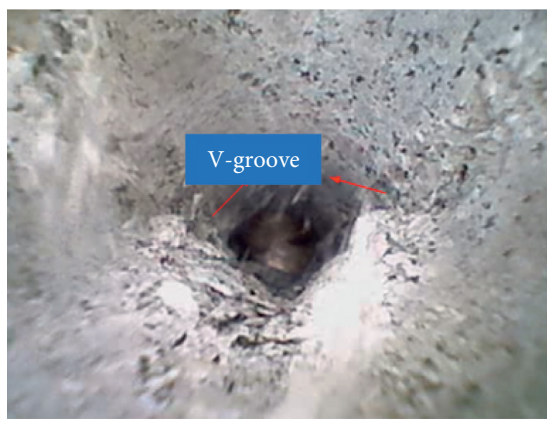

(i)

FIgURE 11: Continued. 


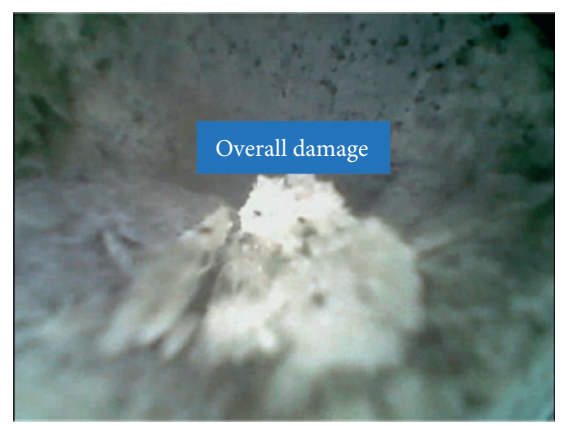

(j)

FiguRE 11: Video capture of the failure process in the marble cave wall, (a) $12^{\prime} 75.32^{\prime \prime}\left(\sigma_{z}=38.68 \mathrm{MPa}\right),(\mathrm{b}) 19^{\prime} 35.22^{\prime \prime}\left(\sigma_{z}=60.88 \mathrm{MPa}\right),(\mathrm{c})$ $20^{\prime} 57.22^{\prime \prime}\left(\sigma_{z}=61.06 \mathrm{MPa}\right),(\mathrm{d}) 27^{\prime} 28.38^{\prime \prime}\left(\sigma_{z}=79.65 \mathrm{MPa}\right),(\mathrm{e}) 31^{\prime} 14.52^{\prime \prime}$ ( $\left.\sigma_{z}=90.84 \mathrm{MPa}\right),(\mathrm{f}) 34^{\prime} 43.38^{\prime \prime}\left(\sigma_{z}=101.53 \mathrm{MPa}\right),(\mathrm{g}) 39^{\prime} 26.08^{\prime \prime}$ $\left(\sigma_{z}=116.65 \mathrm{MPa}\right),(\mathrm{h}) 43^{\prime} 53.32^{\prime \prime}\left(\sigma_{z}=129.03 \mathrm{MPa}\right)$, (i) $49^{\prime} 01.18^{\prime \prime}\left(\sigma_{z}=143.33 \mathrm{MPa}\right)$, (j) $52^{\prime} 73.05^{\prime \prime}\left(\sigma_{z}=155.21 \mathrm{MPa}\right)$.

while the $Z$ direction loading continued at the same rate of $3 \mathrm{MPa} / \mathrm{min}$. When the value $\sigma_{Z}=38.68 \mathrm{MPa}$ was reached, the wall's left side with holes began to fail, and the ejection and spalling of fine particles appeared (see Figure 11(a)). When $\sigma_{Z}$ was increased to $60.88 \mathrm{MPa}$, a small piece of rock ejected on the left side of the wall was found (see Figure 11(b)). At $\sigma_{Z}=61.06 \mathrm{MPa}$, a large piece of rock mass ejected into the cave with a certain initial velocity (see Figure $11(\mathrm{c})$ ). With a gradual increase in $\sigma_{Z}$, there were continuous rock fragments on the cave wall exhibiting spalling and collapse, resulting in the obvious V-groove burst pit formed on both sides of the cave wall (see Figure $11(\mathrm{~d}))$. In the following $3.86 \mathrm{~s}$, two rock fragment cracking occurred in the cracked rock slab, and the splitting structure of the cave wall further developed (see Figure 11(e)), increasing the V-shaped groove length. When $\sigma_{Z}$ was increased to $101.53 \mathrm{MPa}$, the energy accumulated in the sample became larger, the ejection kinetic energy of the slab cracked rock fragments increased, and there were numerous broken rock fragments (see Figure 11(f)). In the following $3.45 \mathrm{~s}$, a V-shaped groove was further developed, and the cracking slab of the cave wall spalled three times (see Figure $11(\mathrm{~g}))$. At $\sigma_{Z}=129.03 \mathrm{MPa}$, the $\mathrm{V}$-shaped rupture pits on both sides of the cave wall developed more violently (see Figure 11(h)), and the fracture of the rock fragments became more pronounced as the stress increased. At $\sigma_{Z}=143.33 \mathrm{MPa}$, the rockburst pit produced only buckling but no ejection (see Figure 11(i). At $\sigma_{Z}=155.21 \mathrm{MPa}$, the sample was entirely broken (see Figure 11(j)).

4.2.2. Failure Evolution Characteristics of Sandstone. The procedure identical to that of marble sample testing was repeated for sandstone samples, except that the true-triaxial loading in $X, Y$, and $Z$ directions was provided with the loading rates of $3,0.5$, and $1 \mathrm{MPa} / \mathrm{min}$, respectively. After loading to the initial stress level, the $X$ and $Y$ stresses remained unchanged, while the loading in the $Z$ direction continued at the loading rate of $3 \mathrm{MPa} / \mathrm{min}$. At $\sigma_{Z}=28.13 \mathrm{MPa}$, the wall's right side with holes began to fail, and the ejection of small particles appeared (see Figure 12(a). When $\sigma_{Z}$ was increased to $34.64 \mathrm{MPa}$, splitting appeared on the right side of the borehole wall, and cracks appeared on the left side (see Figure 12(b)). At $\sigma_{Z}=37.12 \mathrm{MPa}$, a large piece of rock suddenly lost stability and slipped to the middle of the borehole (see Figure 12(c)). With an increase in $\sigma_{Z}$, the degree of the splitting of the cave wall gradually increased, while large and small pieces slipped off, forming obvious fins on both sides of the cave wall (see Figure 12(d)). After $\sigma_{Z}$ was increased to $61.40 \mathrm{MPa}$, the failure of the slabs began to intensify. Two bursts of rock fragments occurred successively from the inside of the cracked rock slab, and the slabs further developed. At $\sigma_{Z}=67.62 \mathrm{MPa}$, the borehole underwent the overall deformation, the bottom shifted upward, and severe failure occurred (see Figure 12(g)). It shows that the rock sample was locally damaged, and the rock sample's overall strength was reduced. As $\sigma_{Z}$ increased, the borehole's overall deformation was accelerated, a large piece of splitting rock fragments in the borehole wall slipped off, and the degree of failure was severe (see Figures 12(h) and $12(\mathrm{j}))$. When $\sigma_{Z}$ was increased to $83.99 \mathrm{MPa}$, the sample was fully broken (see Figure 12(j)).

As shown in Figure 11, when the marble sample was damaged, small particles were ejected first, and the borehole wall had slipping-off flakes, forming symmetrical V-shaped grooves. With the intensified development of slab cracks and further expansion of V-shaped grooves, the entire sample underwent instantaneous failure. In contrast, according to Figure 12, when the sandstone sample was loaded, small particles' ejection occurred first, but this process was relatively short. Then, the borehole wall produced slipping-off flakes without the ejection phenomenon. With the expansion of the slab crack, the borehole wall also formed $\mathrm{V}$-shaped grooves, the entire borehole was deformed, and the bottom shifted upward. The strain rate increased with the axial pressure, and, finally, the whole sample failed. It can be seen that harder rock masses featured fewer fractures and higher degrees of failure. There were obvious V-shaped grooves on both sides of the marble cave wall. The tensile failure occurred near the working surface, and shear failure occurred at a far distance. In contrast, sandstone's complete failure featured mainly tensile cracks, while splitting failure occurred in the area located far away from the working surface. 


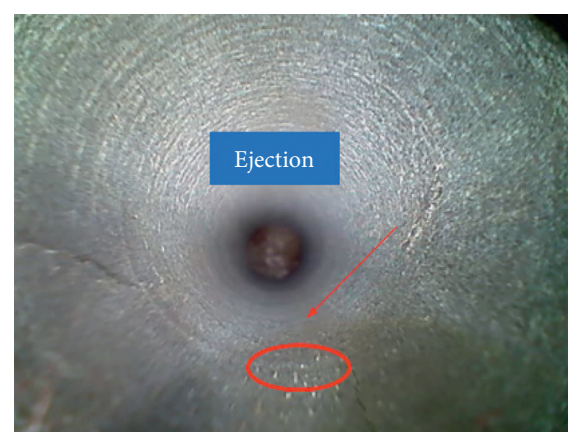

(a)

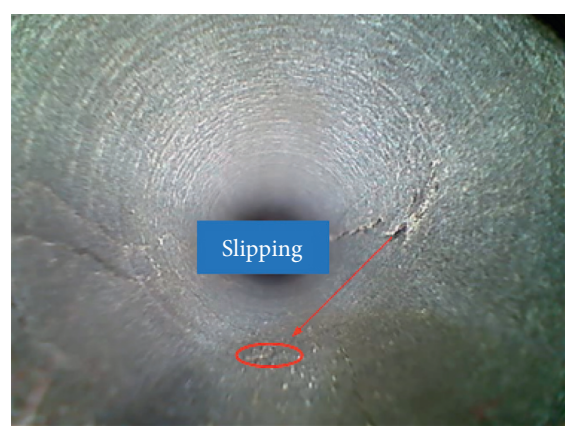

(c)

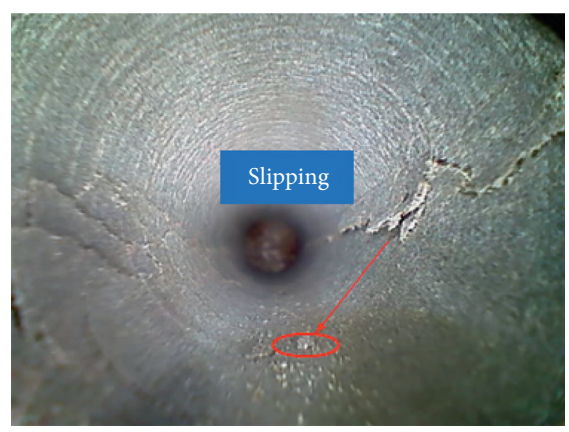

(e)

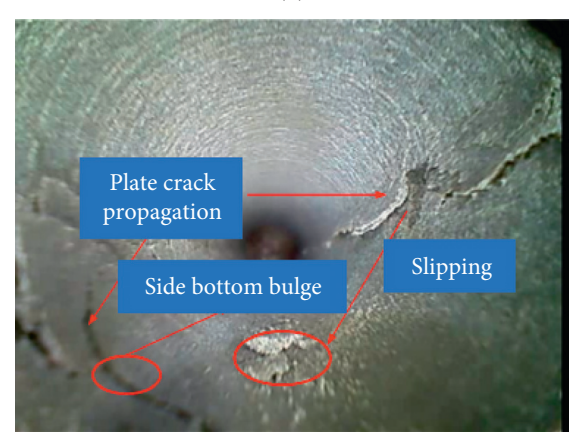

(g)

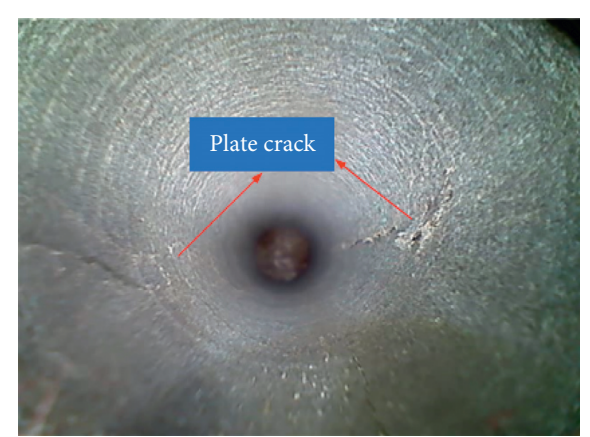

(b)

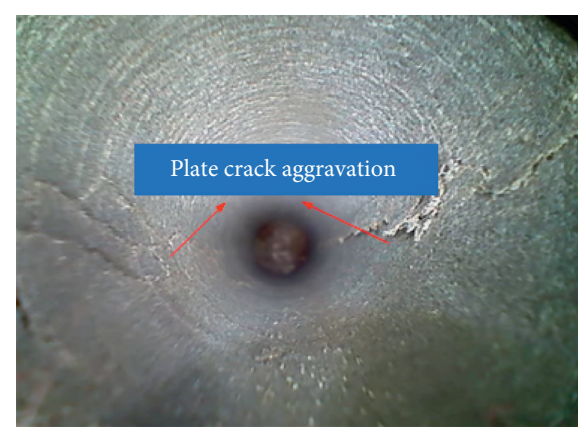

(d)

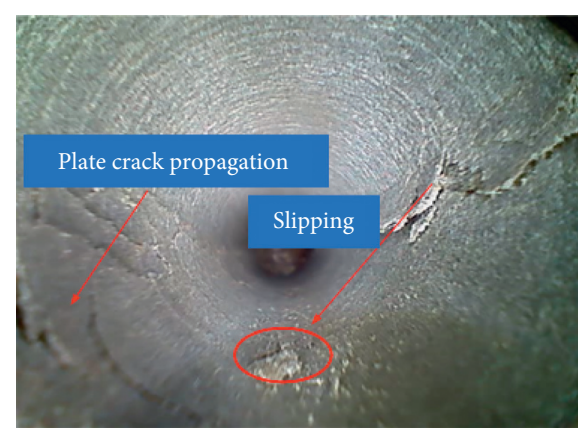

(f)

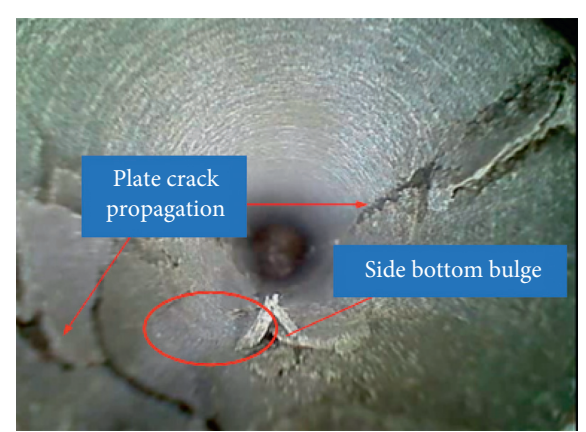

(h)

FIgURE 12: Continued. 


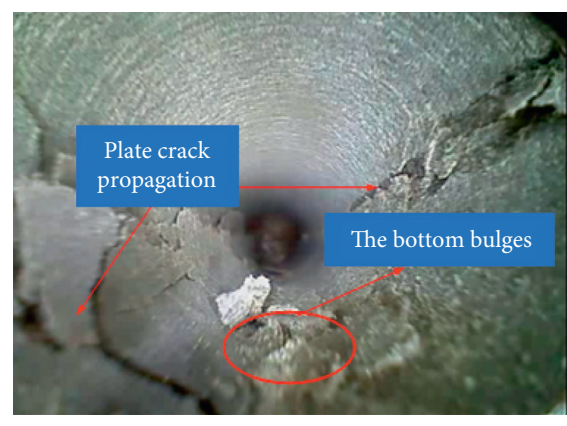

(i)

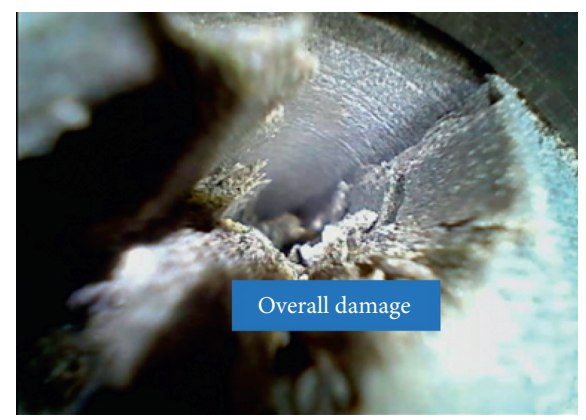

(j)

Figure 12: Video capture of the failure process in the sandstone cave wall, , (a) $16^{\prime} 17.12^{\prime \prime}\left(\sigma_{z}=28.13 \mathrm{MPa}\right),(\mathrm{b}) 18^{\prime} 45.37^{\prime \prime}\left(\sigma_{z}=34.64 \mathrm{MPa}\right)$, (c) $19^{\prime} 28.26^{\prime \prime}$ ( $\left.\sigma_{z}=37.12 \mathrm{MPa}\right),(\mathrm{d}) 22^{\prime} 18.18^{\prime \prime}\left(\sigma_{z}=45.83 \mathrm{MPa}\right),(\mathrm{e}) 24^{\prime} 25.16^{\prime \prime}$ ( $\left.\sigma_{z}=52.05 \mathrm{MPa}\right),(\mathrm{f}) 27^{\prime} 36.38^{\prime \prime}\left(\sigma_{z}=61.40 \mathrm{MPa}\right),(\mathrm{g}) 29^{\prime} 44.12^{\prime \prime}$ $\left(\sigma_{z}=67.62 \mathrm{MPa}\right),(\mathrm{h}) 32^{\prime} 33.25^{\prime \prime}\left(\sigma_{z}=76.01 \mathrm{MPa}\right)$, (i) $33^{\prime} 13.22^{\prime \prime}\left(\sigma_{z}=78.87 \mathrm{MPa}\right),(\mathrm{j}) 34^{\prime} 50.48^{\prime \prime}\left(\sigma_{z}=83.99 \mathrm{MPa}\right)$.

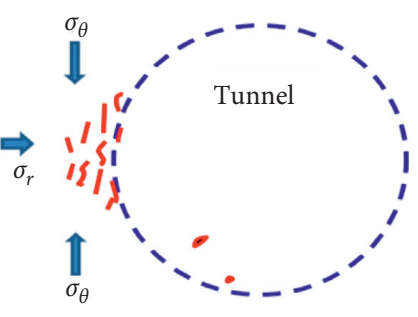

(a)

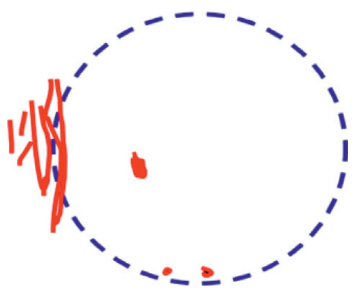

(b)

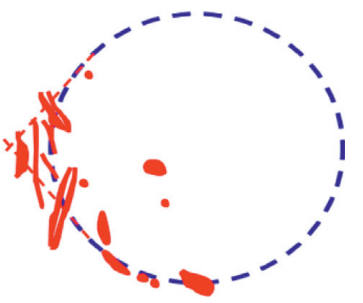

(c)

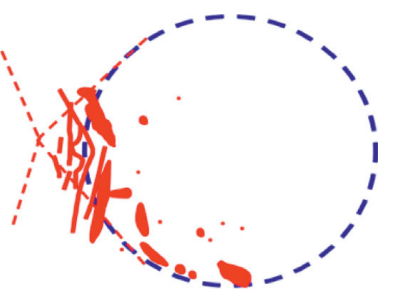

(d)

FIGURE 13: Failure diagram of roadway-surrounding rocks.

In general, failures of roadway-surrounding rocks are shown in Figure 13. Under the effect of tangential stresses, the surrounding rocks contained cracks, which gradually developed and propagated. The surface of the roadwaysurrounding rocks exhibited the ejection of small particles. As the surrounding rocks deformed, they underwent buckling failure, as shown in Figure 13(b). With the stress concentration, the buckling failure of slab cracks of the surrounding rocks aggravated and gradually shifted to the sample bulk, gradually forming $\mathrm{V}$-shaped grooves, as shown in Figure 13(c). Finally, stresses in the stress concentration zone exceeded the rock mass's compressive strength and were abruptly released. With the ejection of particles, the rock slab slid down, and shear failure appeared along the end of the V-shaped groove toward the deep part of the surrounding rocks. This was similar to the in situ failure of surrounding rocks during excavation-induced unloading of the high-stress rock mass.

\subsection{Acoustic Emission Parameters in Failures of Surrounding Rocks during Excavation-Induced Unloading of High-Stress Rock Mass. The ring counts and impact signals in the acoustic emission (AE) system reflect the degree of activity of the rock mass's deformation and failures in different stress-strain processes. The waveform of a signal corre- sponds to an impact, and the duration is related to the waveform sampling rate.}

As shown in Figure 14, when the marble sample was loaded to the initial confining pressure at the first (compaction) stage, the microcracks available in the sample were closed. There were only a few AE events, but AE's cumulative energy continued to increase, indicating that the marble's internal fractures were continuously compressed and closed. On the other hand, this may be because the friction between the testing machine clamps caused the energy to increase. The count of AE events was higher when the sandstone was loaded to the initial confining pressure at the first (compaction) stage. After the initial value of the axial load was increased (in the horizontal direction), the count of $\mathrm{AE}$ events gradually stabilized and became zero, indicating no obvious damage in the rock sample at this stage. When the axial pressure of marble reached $38 \mathrm{MPa}$, the count of $\mathrm{AE}$ events gradually increased, but the ring count remained low and was mostly caused by particles' ejection, while AE events appeared intermittently. When the axial pressure was increased to $65 \mathrm{MPa}$, the count of AE events continued to grow and exhibited a sharp increase, whereas cracks penetrated the borehole-surrounding rocks. When the axial pressure reached $100 \mathrm{MPa}$, the count of $\mathrm{AE}$ events gradually stabilized and saturated. Compared with Figure 11, it can be seen that the axial stress was between 38 and $100 \mathrm{MPa}$, and both sides of the borehole wall were cracked. This process involved a gradual formation of $\mathrm{V}$-shaped grooves, and serious failures occurred in the rock sample. Then, V-shaped grooves gradually expanded, and the count of AE events was in a 


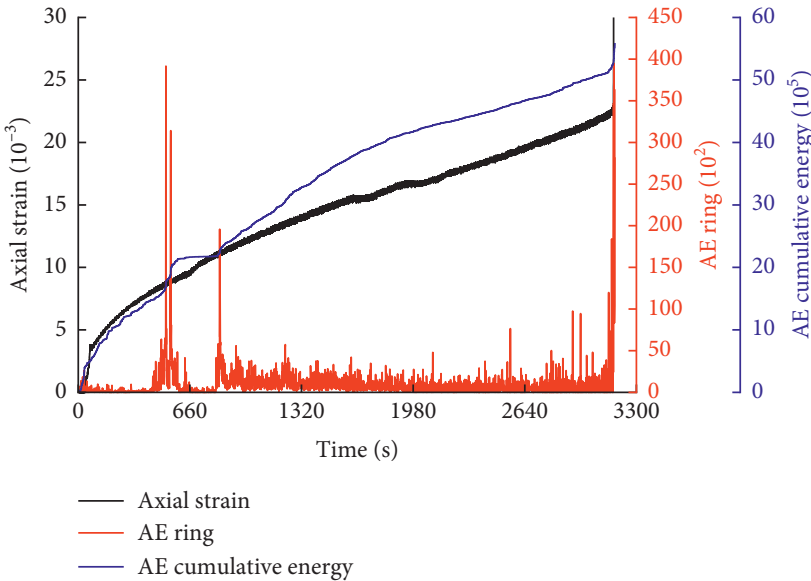

(a)

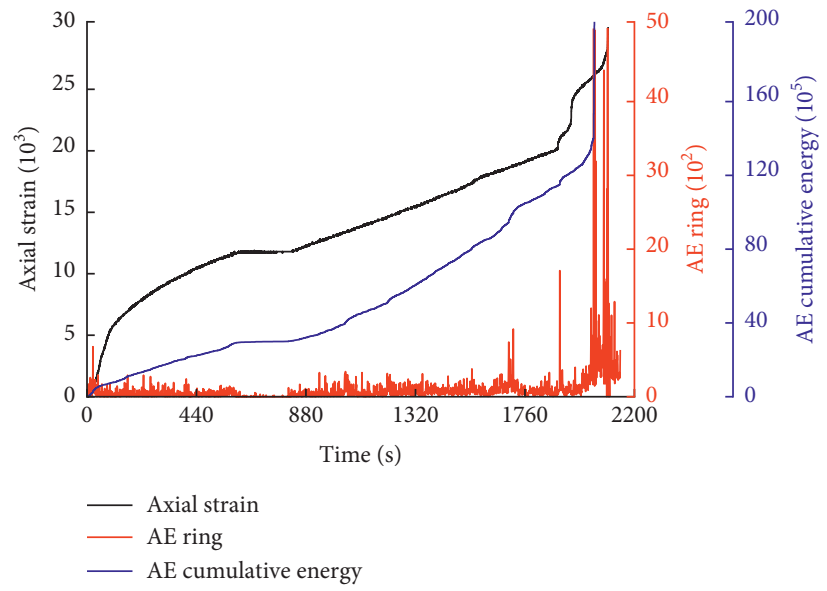

(b)

FIgURE 14: Evolution of stress, strain, count of AE events, and energy of samples. (a) marble and (b) sandstone.

stable state. When the axial stress reached $153 \mathrm{MPa}$, the count of AE events increased sharply, and the rock sample underwent the overall failure. When sandstone's axial pressure was further increased, $\mathrm{AE}$ events continued to occur, which was slightly different from the intermittent process in the marble sample. When the axial pressure reached $30 \mathrm{MPa}$, the count of $\mathrm{AE}$ events exhibited a peak. As the axial pressure continued to increase, the AE hits featured multiple peaks, which gradually increased. The maximum count of AE events was observed at the early stage corresponding to $81 \mathrm{MPa}$, which indicated that, in the process of gradual increase of the specimen axial pressure, macroscopic failure appeared in the sample bulk. According to Figure 12, at the axial pressure of $28.13 \mathrm{MPa}$, both sides of the borehole wall underwent splitting. As the axial pressure increased, the slabs of the borehole wall continued to develop. At the axial pressure of $74 \mathrm{MPa}$, the count of $\mathrm{AE}$ events increased sharply, and severe failures occurred inside the rock sample. When the axial stress reached $83 \mathrm{MPa}$, the count of $\mathrm{AE}$ events increased sharply, and the rock sample underwent the overall failure.

\section{Conclusions}

(1) The fracturing process of tunnel-surrounding rocks during excavation-induced unloading of the high-stress rock mass can be subdivided into the initial compaction stage, linear elastic stage, elastoplastic transition stage, yield or plastic stage, and postpeak stage. The harder the rock sample, the higher its compressive strength. Moreover, the smaller are the peak strains, the more obvious are the yield/plastic stages of harder rock samples with high confining pressures and softer rock samples with low confining pressures. The axial stress drops quickly at the postpeak stage, while the axial strain is very small, showing no (or low) brittleness characteristics under confining pressure conditions.
(2) V-shaped grooves appear at the beginning of the surrounding rock's failure, and splitting appears as the stress increases, and the hole bottom shifts upward. Finally, the overall splitting failure occurs throughout the entire sample, and the bottom bulges upward.

(3) The harder the rock mass, the fewer fractures in the rock mass, and the higher the degree of failure. There are obvious V-shaped grooves on both sides of the marble cave wall. Tensile failure occurs near the opening surface, and shear failure occurs at a far distance. The sandstone's overall failure is related to tensile cracking, and splitting failure occurs in the area away from the opening surface, which is similar to the in situ failure of surrounding rocks during excavation-induced unloading of the high-stress rock mass.

\section{Data Availability}

The datasets generated and analyzed during the current study are available from the corresponding author upon reasonable request.

\section{Conflicts of Interest}

The authors declared no conflicts of interest.

\section{Acknowledgments}

This work was supported by the National Key Research and Development Project of China (2017YFC0603003), National Natural Science Foundation of China (51804119, 51974009, and 51674008), National Natural Science Youth Fund (52004006), Key Research and Development Program of Anhui Province (201904a07020010), Leading Talent Project of Anhui "Special Support Program", Anhui Provincial Academic and Technology Leaders Research Activities Funding (2018D187), Excellence Talent Training Program of 
High School (gxbjZD2016051), and Talent Fund of AUST (13200013).

\section{References}

[1] X. F. Wang, C. G. Liu, S. J. Chen, L. Chen, K. Li, and N. Liu, "Impact of coal sector's de-capacity policy on coal price," Applied Energy, vol. 265, Article ID 114802, 2020.

[2] J. Wang, Y. Zhang, Z. Qin, S. G. Song, and P. Lin, "Analysis method of water inrush for tunnels with damaged waterresisting rock mass based on finite element method-smooth particle hydrodynamics coupling," Computers and Geotechnics, vol. 126, Article ID 103725, 2020.

[3] B. Chen, S. C. Zhang, Y. Y. Li, Z. K. Li, and H. J. Zhou, "Physical simulation study of crack propagation and instability information discrimination of rock-like materials with faults," Arabian Journal of Geosciences, vol. 13, no. 18, Article ID 966, 2020.

[4] X. J. Li, W. S. Zhu, S. C. Li, and W. M. Yang, "A new displacement prediction method of brittle jointed rock mass considering excavation unloading," Chinese Journal of Rock Mechanics and Engineering, vol. 30, no. 8, pp. 1445-1453, 2011, in Chinese.

[5] J. Chen, J. Zhao, S. Zhang, Y. Zhang, F. Yang, and M. Li, “An experimental and analytical research on the evolution of mining cracks in deep floor rock mass," Pure and Applied Geophysics, vol. 177, no. 11, p. 5325, 2020.

[6] D. Liu, Z. Gu, R. Liang et al., "Impacts of pore-throat system on fractal characterization of tight sandstones," Geofluids, vol. 2020, no. 9, 17 pages, Article ID 4941501, 2020.

[7] B. S. Jiang, Q. Zhang, Y. N. He, and L. J. Han, "Elastoplastic analysis of cracked surrounding rocks in deep circular openings," Chinese Journal of Rock Mechanics and Engineering, vol. 29, no. 5, pp. 982-986, 2007, in Chinese.

[8] Y. S. Pan, Y. J. Li, X. Tang, and Z. H. Zhang, "Study on zonal desintegration of rock," Chinese Journal of Rock Mechanics and Engineering, vol. 26, no. S1, pp. 3335-3341, 2007, in Chinese.

[9] Y. M. Song, Y. H. Pan, M. T. Zhang, and H. J. Shi, "Experimental investigation on fracture of three types of underground caverns," Chinese Journal of Rock Mechanics and Engineering, vol. 29, no. S1, pp. 2741-2745, 2010, in Chinese.

[10] X. P. Zhou, M. Zhou, and Q. H. Qian, "Influence of rock damage on zonal disintegration around deep circle tunnels," Chinese Journal of Solid Mechanics, vol. 33, no. 3, pp. 242-250, 2012, in Chinese.

[11] X. N. Wang and R. Q. Huang, "Analysis of deformation and failure features characteristics of rock under unloading conditions and their effects on rock burst," Mountain Research, vol. 16, no. 4, pp. 26-30, 1998, in Chinese.

[12] L. M. Zhang, Z.-Q. Wang, J.-Z. He, and B.-J. Ren, "Study on the experiment of rock burst under unloading condition," Chinese Society of rock Mechanics and Engineering, vol. 24, pp. 4769-4773, 2005.

[13] R. S. Read, "20 years of excavation response studies at AECL's underground research laboratory," International Journal of Rock Mechanics and Mining Sciences, vol. 41, no. 8, pp. 1251-1275, 2004.

[14] C. D. Martin, "Seventeenth Canadian geotechnical colloquium: the effect of cohesion loss and stress path on brittle rock strength," Canadian Geotechnical Journal, vol. 34, no. 5, pp. 698-725, 1997.

[15] S. Kwon, C. S. Lee, S. J. Cho, S. W. Jeon, and W. J. Cho, “An investigation of the excavation damaged zone at the KAERI underground research tunnel," Tunnelling and Underground Space Technology, vol. 24, no. 1, pp. 1-13, 2009.

[16] S. Yong, P. K. Kaiser, and S. Loew, "Rock mass response ahead of an advancing face in faulted shale," International Journal of Rock Mechanics and Mining Sciences, vol. 60, no. 8, pp. 301311, 2013.

[17] W. J. Zhang, W. B. Lu, and J. H. Yang, "Cracking characteristics and influential factors of surrounding rocks induced by excavation unloading in deep tunnel," Rock and Soil Mechanics, vol. 60, no. 8, pp. 2690-2698, 2013.

[18] M. Y. Wang, P. X. Dang, and W. P. Li, "Mechanism of splitting and unloading failure of rock," Chinese Journal of Rock Mechanics and Engineering, vol. 29, no. 2, pp. 234-241, 2010.

[19] H. Li, Q.-M. An, and Y.-C. Ma, "Study on relativity between rock burst and stress state in deep tunnel," Chinese Society of Rock Mechanics and Engineering, vol. 24, pp. 4822-4826, 2005.

[20] C. Q. Zhang, X. T. Feng, and H. Zhou, "Brittle failure of surrounding rock mass in deep test tunnels and its numerical simulation," Chinese Journal of Rock Mechanics and Engineering, vol. 29, no. 10, pp. 2063-2068, 2010, in Chinese.

[21] W. S. Xu, G. M. Zhao, X. R. Meng, and X. Cheng, "Modified D-P criterion based on the double-fold reduction method of the true triaxial single-side unloading strength," Chinese Journal of Rock Mechanics and Engineering, vol. 37, no. 8, pp. 1813-1822, 2018, in Chinese.

[22] W. S. Xu, G. M. Zhao, and X. R. Meng, "Test study on truetriaxial loading and unloading for marble with unloaded single face," Journal of Southwest Jiaotong University, vol. 54, no. 3, pp. 526-534, 2019, in Chinese.

[23] M. S. Diederich, P. K. Kaiser, and E. Eberhardt, "Damage initiation and propagation in hard rock during tunnelling and the influence of near-face stress rotation," International Journal of Rock Mechanics and Mining Sciences, vol. 41, no. 5, pp. 785-812, 2004. 